\title{
Technical Note: Formation of airborne ice crystals in a wall independent reactor (WIR) under atmospheric conditions
}

E. Fries ${ }^{1,{ }^{\star}}$, W. Haunold ${ }^{1}$, E. Starokozhev ${ }^{1}$, K. Palitzsch ${ }^{1}$, R. Sitals ${ }^{1}$, W. Jaeschke ${ }^{1}$, and W. Püttmann ${ }^{1}$

${ }^{1}$ Institute for Atmospheric and Environmental Sciences, Goethe-University,

Frankfurt am Main, Germany

"now at: Institute for Environmental Systems Research, University of Osnabrück,

Osnabrück, Germany

Received: 19 May 2008 - Accepted: 2 June 2008 - Published: 9 July 2008

Correspondence to: E. Fries (fries@usf.uos.de)

Published by Copernicus Publications on behalf of the European Geosciences Union.

Airborne ice crystals in a "virtual wall" reactor

E. Fries et al.

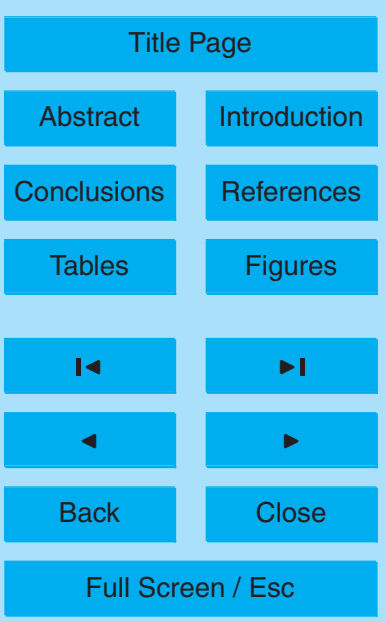

Printer-friendly Version

Interactive Discussion

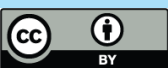




\section{Abstract}

Both, gas and particle scavenging contribute to the transport of organic compounds by ice crystals in the troposphere. To simulate these processes an experimental setup was developed to form airborne ice crystals under atmospheric conditions. Experiments 5 were performed in a wall independent reactor (WIR) installed in a walk-in cold chamber maintained constantly at $-20^{\circ} \mathrm{C}$. Aerosol particles were added to the carrier gas of ambient air by an aerosol generator to allow heterogeneous ice formation.

Temperature variations and hydrodynamic conditions of the WIR were investigated to determine the conditions for ice crystal formation and crystal growth by vapour deposition. In detail, the dependence of temperature variations from flow rate and temperature of the physical wall as well as temperature variations with an increasing reactor depth were studied. The conditions to provide a stable aerosol concentration in the carrier gas flow were also studied.

The temperature distribution inside the reactor was strongly dependent on flow 15 rate and physical wall temperature. At an inlet temperature of $-20^{\circ} \mathrm{C}$, a flow rate of $30 \mathrm{~L} \cdot \mathrm{min}^{-1}$ and a physical wall temperature of $+5^{\circ} \mathrm{C}$ turned out to provide ideal conditions for ice formation. At these conditions a sharp and stable laminar down draft "jet stream" of cold air in the centre of the reactor was produced. Temperatures measured at the chamber outlet were kept well below the freezing point in the whole reactor depth of $1.0 \mathrm{~m}$. Thus, melting did not affect ice formation and crystal growth. The maximum residence time for airborne ice crystals was calculated to at $40 \mathrm{~s}$. Ice crystal growth rates increased also with increasing reactor depth. The maximum ice crystal growth rate was calculated at $2.82 \mathrm{mg} \cdot \mathrm{s}^{-1}$.

Further, the removal efficiency of the cleaning device for aerosol particles was $99.8 \%$ $15 \mathrm{~min}$. Thus, the minimum lead time was determined at $25 \mathrm{~min}$. Several test runs revealed that the WIR is suitable to perform experiments with airborne ice crystals.

Airborne ice crystals in a "virtual wall" reactor

E. Fries et al.

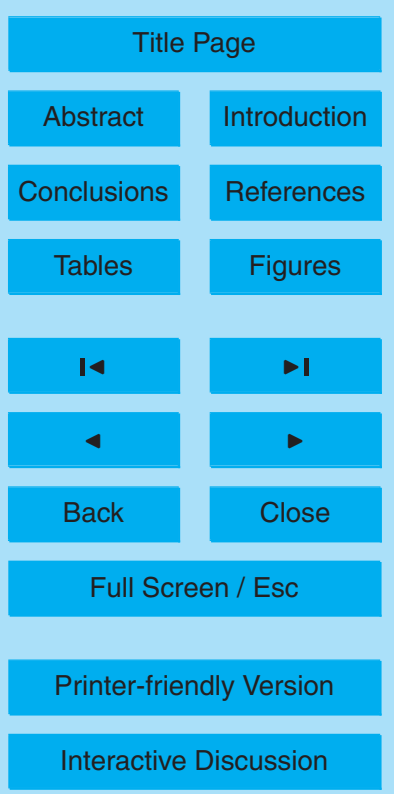




\section{Introduction}

The occurrence of hydrocarbons in snow and ice from high altitudes and latitudes and the importance of ice in the troposphere for the transport of hydrocarbons to remote areas have been reported by several authors (for review see Fries, 2008). Many lab5 oratory experiments were performed to simulate ice-hydrocarbon interactions under equilibrium conditions. Several authors modified the gas chromatographic retention method of Hartkopf and Karger (1973) using a column containing ice-coated material to determine ice surface-air partition coefficients (Goss, 1993; Hoff et al., 1995; Roth et al., 2004). Ice-hydrocarbons interactions were also measured by determining nitro10 gen Brunnauer-Emmett- Teller (BET) areas (Orem and Adamson, 1969). Experiments with non-growing ice crystals were performed to simulate the adsorption of gaseous alkylbenzenes on ice surfaces at different temperatures and different gas phase concentrations (Fries et al., 2006). Most studies under equilibrium conditions revealed that adsorption processes are highly reversible for hydrocarbons. Therefore, the trans15 port of hydrocarbons to remote areas and their occurrence in snow and ice cannot be explained only by equilibrium processes.

Laboratory experiments studying the importance of dynamic processes involved in ice-hydrocarbon interactions are rather limited. One important prerequisite for these studies is the simulation of ice formation and growth in the laboratory under atmospheric conditions. Several approaches were utilized by developing different ice growth reactors. In the studies of Huffman and Snider (2004) ice was deposited on a cooled borosilicate glass used as an ice substrate. Fries et al. (2007) performed uptake experiments with ice crystals grown by vapour deposition on an aluminium extruded heat sink from a supersaturated ambient air stream. However, with such experimental se-

This issue was addressed in several experiments based on adiabatic expansion of air with relative humidity <100\% (Benz et al., 2007; Bunz et al., 1996; Möhler et al., 1999). Another approach was based on the continuous flow diffusion principle (Rogers,

ACPD

8, 13017-13042, 2008

\section{Airborne ice crystals in a "virtual wall" reactor \\ E. Fries et al.}

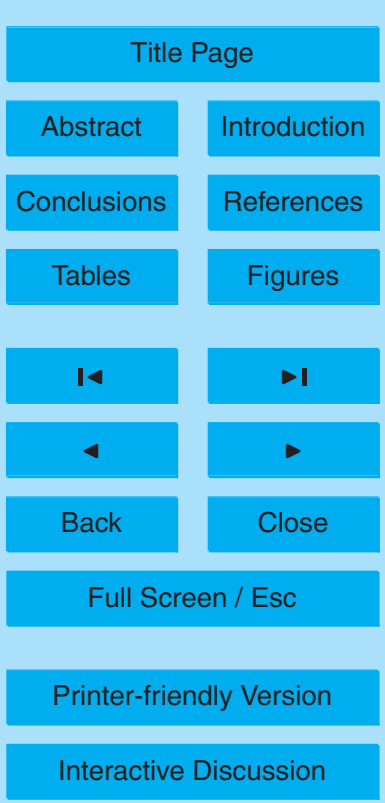


1988, 1994, 2001; de Mott et al., 2003; Salam et al., 2006). The experimental design of Bundke et al. (2008) allowed the mixing of air masses kept at different temperatures and humidity. A slightly different method to attain supersaturation with respect to ice was developed by cooling a warm humid air stream as conducting it through a cold

5 environment (Wex et al., 2006; Stratmann et al., 2004). However, direct mixing of air masses usually requires huge quantities of cold air and wall effects have to be also considered. In order to minimize wall effects, to overcome turbulences and to ensure a stable air flow an additional flow of sheath air could be necessary.

In this paper we present a new wall independent reactor (WIR) to simulate the for10 mation of airborne ice crystals unaffected by wall effects and without requiring sheath air. This setup is appropriate to identify important parameters controlling ice formation in mixed phase clouds as hydrodynamic parameters, temperature, humidity and type of aerosol particles acting as ice nuclei. With the WIR the study of interactions of hydrocarbons and other organic compounds with airborne ice crystals under atmospheric conditions will be possible. With this design it will be also possible to distinguish between gas and nucleation scavenging of organic compounds by airborne ice crystals.

\section{Experimental setup}

\subsection{Wall independent reactor (WIR) and temperature measurements}

Airborne ice crystals were generated in a vertical wall independent reactor (WIR) $(1.0 \mathrm{~m}$ in length and $0.3 \mathrm{~m}$ in diameter) under atmospheric pressure. The WIR was located inside a $3.0 \mathrm{~m} \times 2.0 \mathrm{~m}$ walk-in cold chamber maintained at $-20^{\circ} \mathrm{C}$. To avoid influence of the chamber temperature the reactor was isolated. The experimental setup and the related gas flow scheme are shown in Fig. 1a. Pressurized ambient air ( 2 bar, temperature at $+20^{\circ} \mathrm{C}$ ) was pumped in a $1 / 2$ " diameter Teflon tube through a cleaning device consisting of two activated charcoal filters, a molecular sieve and a Teflon filter (Sartorius $0.2 \mu \mathrm{m}$ ) to eliminate background contamination of organic gases and particles. The

Airborne ice crystals in a "virtual wall" reactor

E. Fries et al.

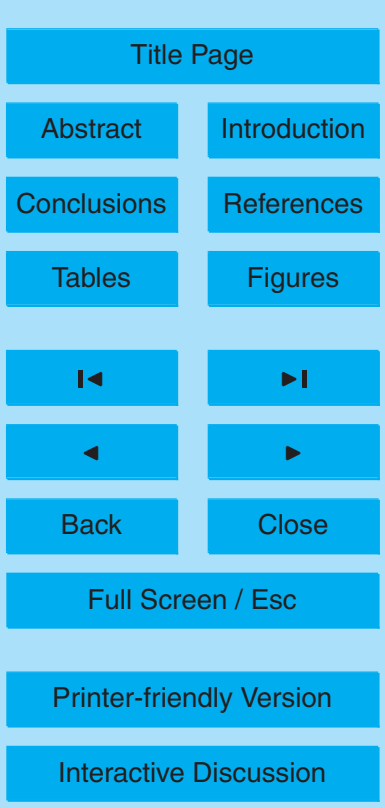


efficiency of the cleaning device with respect to particle removal from outside air was controlled by measuring particles in the air flow with a particle counter (KRATEL Partoscope A, KRATEL GmbH \& Co. KG, Leonberg-Ramtel, Germany) after the flow passed the cleaning device. Flow adjustment was performed by a mass flow controller (MFC

5 type 2259 C, MKS Instruments, Germany). Excess moisture was removed from the air stream by a cold trap maintained at $-10^{\circ} \mathrm{C}$ before entering the walk-in cold chamber. Inside this chamber the air stream was transported in a helical flexible aluminium vent duct (System 300AC Lindab, Germany) with a length of $5.5 \mathrm{~m}$ and a diameter of $0.05 \mathrm{~m}$ for heat exchange. The air stream was adjusted to the chamber temperature of $-20^{\circ} \mathrm{C}$ 10 before it entered the inlet of the WIR. All excess moisture in the air was removed which led to saturated conditions over ice at the inlet of the reactor. The air flow smoothly entered the chamber. Once the cold and saturated air mass entered the reactor it flows vertically over a total distance of $1.0 \mathrm{~m}$ almost in the reactor centre.

Inside the reactor, supersaturation was obtained in the air stream by molecular water 15 vapour diffusion from a physical wall along the chamber radius of $0.15 \mathrm{~m}$ into the laminar sharp down draft "jet stream" of cold air in the centre. Therefore, the reactor was double-walled over a length of $0.7 \mathrm{~m}$ with a filter paper (type 541, Whatman, Schleicher \& Schuell, Germany) mounted at the inner wall of the reactor in a reactor depth between $0.18 \mathrm{~m}$ and $0.88 \mathrm{~m}$. The temperature of the physical wall was controlled by a cryostat. This allows the diffusive release of water vapour from the filter paper into the central "jet stream". With this approach the caloric influence of the wall is minimized.

In Fig. 1a, temperature measurement points are shown (T). Measurements of the inlet and outlet temperature of the WIR were performed with glass-mantled resistance temperature detectors (RTDs; type PT100, Heraeus). For temperature measurement inside the reactor, four PT100 temperature sensors were mounted as follows: Four sticks screwed at right angles into a supporting rod at distances of $0.2,0.4,0.6$ and $0.8 \mathrm{~m}$ over the length of the rod. The four temperature sensors were attached to the tip of a stick. The rod pivot was mounted perpendicular to the bottom of the chamber (see Fig. 1a). With this design it was possible to perform temperature scans in four

\section{Airborne ice crystals in a "virtual wall" reactor}

E. Fries et al.

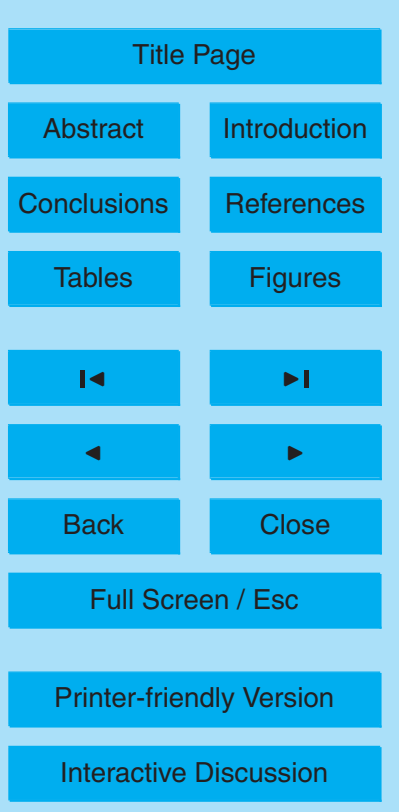


different reactor depth and six points in each depth. According to the symmetry of the chamber, temperatures across the diameter were inferred from those measured over the radius. Together with the temperature measurements at the inlet and outlet of the reactor temperature profiles from 50 points were recorded. Furthermore, two PT100s 5 were placed directly on the filter paper resulting in 52 temperature measuring points in total. Areas between the supporting points were numerically interpolated using SPLUS software (professional edition, version 6.1.2, Insightful Corp., USA).

The operating principle of the reactor was tested and verified by analysing the temperature distribution inside the reactor to attain ideal temperature conditions for ice 10 crystal formation and growth. First series of experiments the flow rate of the incoming cold air was maintained at $30 \mathrm{~L} \cdot \mathrm{min}^{-1}$ and $20 \mathrm{~L} \cdot \mathrm{min}^{-1}$, respectively. In addition experiments were also performed without a flow of outside air (flow rate at $0 \mathrm{~L} \bullet \mathrm{min}^{-1}$ ). During these experiments the physical wall which is represented by the temperature at the wetted filter paper, and the walk-in chamber temperature were maintained constantly at $+5^{\circ} \mathrm{C}$ and $-20^{\circ} \mathrm{C}$, respectively. In a second series of experiments the physical wall temperature was decreased from $+10.0^{\circ} \mathrm{C}$ to $9.4^{\circ} \mathrm{C}$ and finally to $+6.3^{\circ} \mathrm{C}$ whereas the inlet temperature of the outside air and the flow rate were kept constantly at $-20^{\circ} \mathrm{C}$ and $30 \mathrm{~L} \cdot \mathrm{min}^{-1}$, respectively.

\subsection{Hydrodynamic considerations and ice mass calculation}

20 To optimize dimensions and process parameters of the WIR some hydrodynamic parameters were calculated. The Reynolds number $(\mathrm{Re})$ was calculated by

$\operatorname{Re}=\frac{v \cdot l}{\eta_{\text {air }}}$

where $v$ is the flow velocity $\left(\mathrm{m}^{\circ} \mathrm{s}^{-1}\right), \mathrm{I}(\mathrm{m})$ is the characteristic length and $\eta_{\text {air }}$ the kinematical viscosity of air $\left(\mathrm{m}^{2} \bullet \mathrm{s}^{-1}\right)$. Re $<2320$ represents laminar conditions whereas at

$\mathrm{Re}>2320$ flow conditions are turbulent.

Airborne ice crystals in a "virtual wall" reactor

E. Fries et al.

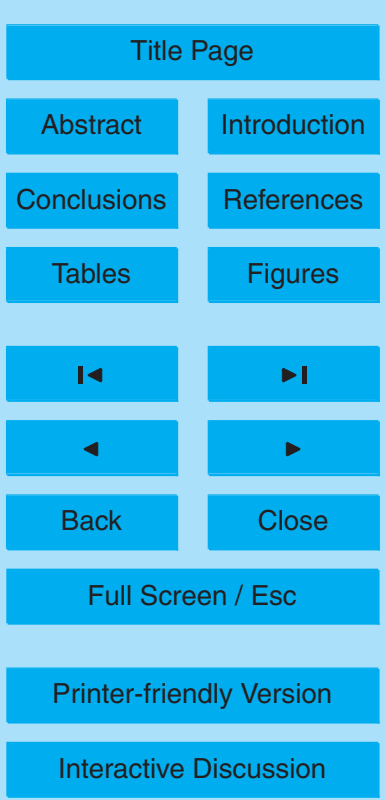

Interactive Discussion 
The Peclet number $(\mathrm{Pe})$ represents the ratio of convective diffusion to molecular diffusion and is given by

$\mathrm{Pe}=\frac{v \cdot l}{D_{T}}$

where $D_{T}\left(\mathrm{~m}^{2} \bullet \mathrm{s}^{-1}\right)$ is the diffusion coefficient of water vapour.

5 The Prandtl number (Pr) characterizes the transport of matter and momentum. It is the ratio of internal friction heat to the heat dissipation by convection and is given by

$\operatorname{Pr}=\frac{\operatorname{Pe}}{\operatorname{Re}}=\frac{\eta_{\text {air }}}{D_{T}}$

$\operatorname{Pr} \leq 1$ represents convective mass transport.

Ice growth rates were determined from the distribution of water vapour concentration

10 (calculated from the measured temperatures at a relative humidity of $100 \%$ ) across the profile of the reactor. Assuming the amount of water vapour exceeds the amount needed for ice crystal formation and does therefore not limit the process, and the mass transport is characterized by molecular and convective diffusion at the same time, the accumulated amount of water vapour involved in ice crystal growth is given by

$\mathrm{Q}=\mathrm{Q}_{C}+\mathrm{Q}_{M}$

where $\mathrm{Q}\left(\mathrm{mg}^{\bullet} \mathrm{s}^{-1}\right)$ is the transported mass per time unit representing the ice growth rate, $Q_{C}\left(\mathrm{mg}^{\bullet} \mathrm{s}^{-1}\right)$ is the mass transported by convection and $\mathrm{Q}_{M}\left(\mathrm{mg} \bullet \mathrm{s}^{-1}\right)$ is the mass transported by molecular diffusion. This calculation was made under the assumption that the water vapour budget for ice crystal growth in the lower zones of the reactor

results from the portion initially present in the incoming air stream plus that which is stored at the wetted filter paper. The latter is released into the convective air flow by molecular diffusion. The convectively transported amount of water vapour at the inlet zone $\mathrm{Q}_{C}\left(\mathrm{mg} \mathrm{s}^{-1}\right)$ is calculated by

$Q_{C}=C \cdot v \cdot A$

Airborne ice crystals in a "virtual wall" reactor

E. Fries et al.

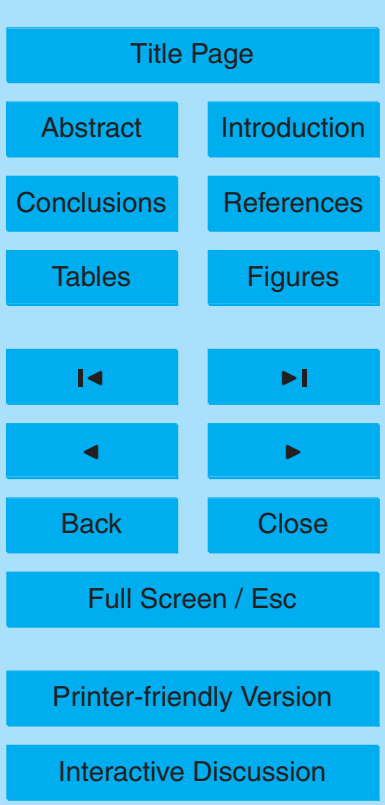

Interactive Discussion 
where $\mathrm{C}\left(\mathrm{g} \mathrm{m}^{-3}\right)$ is the water vapour concentration at the corresponding inlet temperature and relative humidity of $100 \%$, and $v\left(\mathrm{~m}^{\circ} \mathrm{s}^{-1}\right)$ is the flow velocity over the crosssection $A\left(\mathrm{~m}^{2}\right)$ of the reactor. The whole portion $Q_{M}$ supplied by molecular diffusion from the physical wall at each height element $h(h=0.1 \mathrm{~m})$ was calculated by Nernst 5 equation

$\mathrm{Q}_{M}=\sum_{i=1}^{n} \mathrm{Q}_{\mathrm{M}, \mathrm{i}}$

with

$\mathrm{Q}_{M, i}=\mathrm{J}_{m} \cdot \mathrm{A}_{s h}=\Delta C \cdot \sqrt{\frac{D_{T} \cdot v}{2 h}} 2 \pi \cdot \mathrm{R} \cdot \mathrm{h}$

$Q_{M, i}\left(m^{\circ} s^{-1}\right)$ is the ice mass grown by molecular diffusion per time at a certain height 10 element $h, J_{m}\left(m^{\circ} \mathrm{m}^{-2} \cdot \mathrm{s}^{-1}\right)$ is the mass flow, $A_{s h}\left(m^{2}\right)$ is the inner shell surface of the considered section given by its radius $R(m)$ and its height $h(m), v\left(m \bullet s^{-1}\right)$ is the flow velocity over the chamber cross-section, and $\Delta \mathrm{C}\left({\left.\mathrm{g} \bullet \mathrm{m}^{-3}\right)}^{-}\right.$corresponds to the difference of water vapour concentration between cold air at the reactor centre and warm moist air at the walls in a certain reactor depth. The saturation ratio (S) in a different reactor 15

$\mathrm{S}=\frac{\mathrm{C}}{\mathrm{C}_{\mathrm{sat}}}$

where $\mathrm{C}\left(\mathrm{g} \cdot \mathrm{m}^{-3}\right)$ is the concentration of water vapour in the air flow as calculated by $\mathrm{Eq}$. (5), and $\mathrm{C}_{\text {sat }}\left(\mathrm{g} \cdot \mathrm{m}^{-3}\right)$ represents the water vapour concentration at saturated conditions for the mean values of measured temperatures over a certain cross-section
ACPD

8, 13017-13042, 2008

Airborne ice crystals in a "virtual wall" reactor

E. Fries et al.

Title Page

Abstract

Introduction

Conclusions

References

Tables

Figures

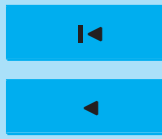

$\rightarrow$

Back

Close

Full Screen / Esc

Printer-friendly Version

Interactive Discussion 


\subsection{Supply of aerosol particles}

Aerosol particles were supplied by an aerosol generator. The principle of particle generation is shown in Fig. 1b. To enable heterogeneous ice nucleation, Sahara dust (by courtesy of Dr. L. Schütz from Mainz University) was added to the inlet of the WIR.

5 A partial air flow of $2.5 \mathrm{~L} \bullet \mathrm{min}^{-1}$ was taken from the main flow at approximately half of the length of the aluminium vent duct (see Fig. 1a). Flow adjustment and control was again performed by a mass flow controller (MFC type 2259 C, MKS Instruments, Munich, Germany). The partial flow was led through a self-made aerosol generator to enrich the ambient air with aerosol particles. The aerosol generator itself operated as follows: A vial on a magnetic hot plate contained the aerosol sample and was connected with a dispenser flask. Since the aerosol generator was placed inside the walk-in cold chamber, the hot plate was heated to $+60^{\circ} \mathrm{C}$ to prevent the aerosol particles from freezing-induced agglomeration. While the aerosol particles were dispersed by stirring with a magnetic stirrer (RPM $100 \mathrm{~min}^{-1}$ ), a small scavenging flow was blown 15 with $0.5 \mathrm{~L} \cdot \mathrm{min}^{-1}$ onto the particles to support the dispersion. A second air flow was added with a flow rate of $2 \mathrm{~L} \bullet \mathrm{min}^{-1}$ to raise the particles and to transport them directly into the inlet of the WIR. Right at the inlet the partial air flow enriched with particles was merged again with the main flow of ambient air. The stability of the aerosol generation was tested by measuring the aerosol particles with the particle counter KRATEL Partoscope A.

\section{Results and discussions}

Main processes possibly influence ice formation inside the WIR are (i) evaporation of water from the physical wall and transport of water vapour into the cold "jet stream" by molecular diffusion, (ii) ice formation and water vapour depositional growth of ice crystals at temperatures below $0^{\circ} \mathrm{C}$, and (iii) melting of ice crystals at temperatures above $0^{\circ} \mathrm{C}$.

Airborne ice crystals in a "virtual wall" reactor

E. Fries et al.

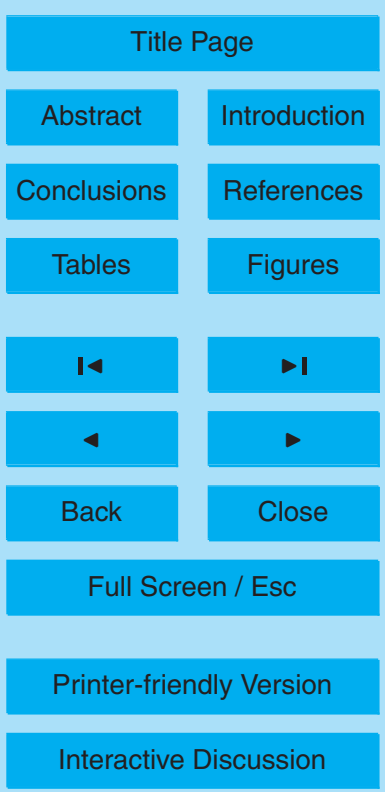

Interactive Discussion 
Temperature profiles that characterize the processes inside the WIR are shown in Fig. 2. Figure $2 a$ illustrates the temperature profiles measured at different flow rates at a constant physical wall temperature of $+5^{\circ} \mathrm{C}$ and an inlet temperature of $-20^{\circ}$. At a flow rate of $30 \mathrm{~L} \bullet \mathrm{min}^{-1}$ a stable cold "jet stream" was achieved in the centre of the 5 reactor. However, at an air flow of $20{\mathrm{~L} \bullet \mathrm{min}^{-1}}^{-1}$ the cold jet stream in the reactor centre lost its stability before passing the reactor outlet resulting in a more diffuse temperature profile. To verify whether the "jet stream" in the centre was actually caused by the throughput of cold inlet air and not by any undefined turbulences the centre flow was stopped. An immediate break-down of the cold "jet stream" occurred once the flow 10 reached $0 \mathrm{~L} \cdot \mathrm{min}^{-1}$.

Our results demonstrate that a reduced flow rate interferes with the conditions for ice crystal formation and growth inside the reactor. A higher flow rate leads to a more distinct and stable centre flow. However, a higher flow rate decreases also the residence time and therefore the potential for ice formation. The number of water vapour molecules that can diffuse from the moist walls to the centre within the considered timeframe is also decreased. A lower residence time decreases the potential for ice formation and shortens also reaction time. The corresponding residence time to a flow rate of $30 \mathrm{~L} \cdot \mathrm{min}^{-1}$ in the effective reaction zone (zone characterized by supersaturated conditions over ice) ranged from 28 to $40 \mathrm{~s}$ depending on the point where the vertical gas flow and the lateral flow of water vapour start to overlap. According to de Mott et al. (2003) ice crystals were formed at residence times of 20 to $30 \mathrm{~s}$. Thus, we conclude that the residence time under this experimental conditions is sufficient for the activation of ice nuclei and a flow rate of $30 \mathrm{~L} \bullet \mathrm{min}^{-1}$ was defined as an optimum at an inlet temperature of $-20^{\circ} \mathrm{C}$.

Figure $2 \mathrm{~b}$ shows the temperature profiles measured at different temperatures of the physical wall of $+10.0^{\circ} \mathrm{C},+9.4^{\circ} \mathrm{C}$ and $+6.3^{\circ} \mathrm{C}$ at a constant flow of $30 \mathrm{~L} \cdot \mathrm{min}^{-1}$ and an inlet temperature of $-20^{\circ} \mathrm{C}$. A physical wall temperature of $+10^{\circ} \mathrm{C}$ leads to temperatures $>0^{\circ} \mathrm{C}$ at the reactor outlet, and ice crystal growth was not possible. As the wall temperature was decreased to $9.4^{\circ} \mathrm{C}, 6.3^{\circ} \mathrm{C}$ and finally to $5^{\circ} \mathrm{C}$ (see Fig. 2a) a "jet stream"

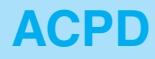

8, 13017-13042, 2008

\section{Airborne ice crystals in a "virtual wall" reactor}

E. Fries et al.

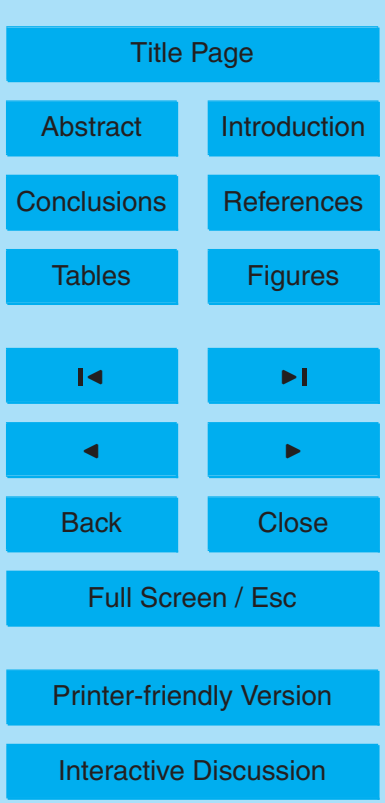


was developed characterized by a zone of cold, saturated air masses in the reactor centre. Our results show that the temperature characteristics inside the reactor are also strongly dependent on the physical wall temperature. Even slight changes of this parameter considerably affect the stability of the cold "jet stream" in the centre which

5 is necessary for ice formation. The best conditions for ice crystal growth in the reactor were achieved at an inlet temperature of $-20^{\circ} \mathrm{C}$, a physical wall temperature of $+5^{\circ} \mathrm{C}$ and a flow rate of $30 \mathrm{~L}^{-1}$ (the corresponding temperature profile is shown in the top left-hand corner of Fig. 2a).

Temperature profiles measured at the centre of the jet stream in a different reac10 tor depth at ideal conditions (inlet temperature of $-20^{\circ} \mathrm{C}$, physical wall temperature of $+5^{\circ} \mathrm{C}$, and flow rate of $30 \mathrm{~L} \bullet \mathrm{min}^{-1}$ ) are shown in Fig. 3 . With an increasing depth the temperature in the centre jet stream increased. However, the temperature remained below $0^{\circ} \mathrm{C}$ at $-5.4^{\circ} \mathrm{C}$ at the chamber outlet. This ensures that ice formation is not affected by melting processes in the whole reactor depth. A linear extrapolation of the

15 temperature line indicated that the temperature would exceed $0^{\circ} \mathrm{C}$ at reactor length of $1.28 \mathrm{~m}$. For ice crystal formation at least temperatures below $0^{\circ} \mathrm{C}$ are needed. Our results demonstrate that temperatures are adequate for ice formation in the whole reactor depth of $1.0 \mathrm{~m}$.

At ideal conditions (inlet temperature of $-20^{\circ} \mathrm{C}$, physical wall temperature of $+5^{\circ} \mathrm{C}$, 20 and flow rate of $30 \mathrm{~L} \cdot \mathrm{min}^{-1}$ ) temperatures at different distances from the reactor centre up to $0.15 \mathrm{~m}$ in a different reactor depth between 0.18 and $0.88 \mathrm{~m}$ are plotted in Fig. 4 . In general, the temperature increased with greater distances from the reactor centre due to the greater influence of the physical wall temperature. Again, the temperature of the jet stream in the reactor centre (line for $0 \mathrm{~cm}$ distance in Fig. 4) increased with an 25 increasing reactor depth. At a distance of $0.03 \mathrm{~m}$ from the reactor centre the temperature increased also with an increasing reactor depth. This could be attributed to the caloric gain of the cold air mass caused by the incorporation of water vapour. However, at greater distances of $0.05 \mathrm{~m}, 0.08 \mathrm{~m}, 0.10 \mathrm{~m}$ and $0.11 \mathrm{~m}$ from the reactor centre the temperature increased up to a reactor depth of $0.45 \mathrm{~m}$, remained nearly constant up

\section{Airborne ice crystals in a "virtual wall" reactor \\ E. Fries et al.}

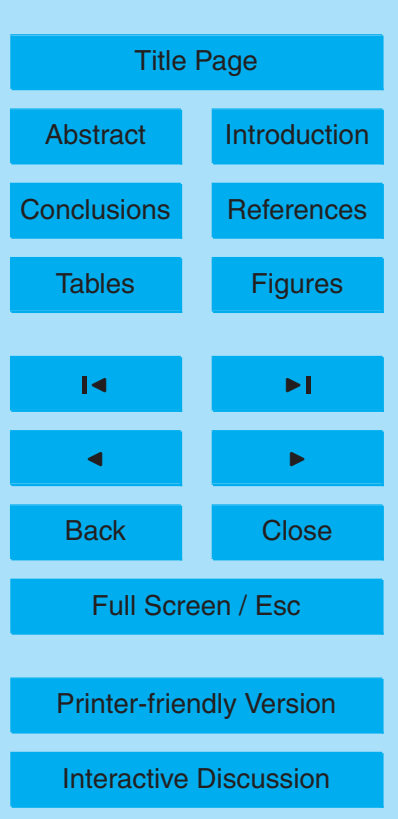

\section{7}


to a reactor depth of $0.65 \mathrm{~m}$ and finally decreased slightly in a reactor depth greater than $0.65 \mathrm{~m}$. This area must represent an overlapping area of the cold "jet' and the warm moist air. Finally as distances from the reactor centre increased to $0.12 \mathrm{~m}$ and $0.15 \mathrm{~m}$, respectively temperatures decreased continuously with an increasing reactor 5 depth. The distances of $0.15 \mathrm{~m}$ represented the temperature at the physical wall.

The two inflection points of the temperature lines for distances from the reactor centre of $0.05 \mathrm{~m}, 0.08 \mathrm{~m}, 0.10 \mathrm{~m}$ and $0.11 \mathrm{~m}$ in a reactor depth of 0.45 and $0.65 \mathrm{~m}$, respectively must reflect a change of hydrodynamic conditions. Thus, they were used to divide the reactor into three sections as illustrated in Fig. 5. Table 1 shows the dif10 ference of the water vapour concentration between the physical wall and the reactor centre $(\Delta \mathrm{C})$ with an increasing reactor depth. The relative depth accounts for the fact that the filter paper was mounted only in a reactor depth from $0.18 \mathrm{~m}$ to $0.88 \mathrm{~m}$. $\Delta \mathrm{C}$ decreased with an increasing reactor depth from $5.25 \mathrm{~g} \bullet \mathrm{m}^{-3}$ to $2.24 \mathrm{~g} \bullet \mathrm{m}^{-3}$ according to the influence of molecular and convective diffusion in each chamber element. A first 15 Sect. $\mathrm{h} 1$ in a reactor depth between $0-0.45 \mathrm{~m}$ is estimated to be influenced mainly by the reactor inlet. Due to a Reynolds number calculated by Eq. (1) of 849 , the flow in this section must be laminar with slight lateral turbulence resulting from friction at the walls and the widening of the cold air stream. The remaining turbulence and the low amount of water vapour which can solely diffuse by convection could reduce ice crystal formation in Sect. h1. The minimum of the centre temperature and the maximum of the wall temperature were detected in this section. This leads to a great temperature and water vapour difference (see Table 1) between the physical wall and the reactor centre. The cold air stream then must slow down and reach the second Sect. h2 of the reactor in a $0.45 \mathrm{~m}$ reactor depth. This section between 0.45 and $0.65 \mathrm{~m}$ can be called a hydrodynamic transient zone as Reynolds number decreased from 849 to 140 indicating a laminar flow. Ice crystal formation must be still marginal in this section because the interaction between the cold air stream and the moist air still develops. However, temperature differences between the physical wall and the reactor centre were smaller than in Sect. h1 (see Fig. 4). In a reactor depth of $0.65 \mathrm{~m}$ temperature

Airborne ice crystals in a "virtual wall" reactor

E. Fries et al.

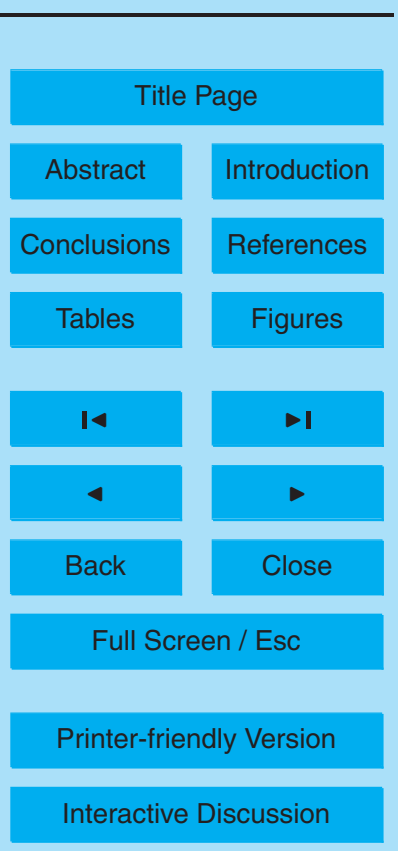


differences decreased again indicating a third Sect. h3 inside the reactor. Within this section flow conditions were determined to be strictly laminar $(R e=140)$. With a Peclet number of 95 and a Prandtl number of 0.67 it is obvious that molecular diffusion as well as free and forced convection take place in this section. At the end of this zone, 5 the difference of temperature and water vapour concentration (see Table 1) between the reactor wall and the "jet stream" reached a minimum. An optimal mixing of the cold "jet" and the warm moist air over the reactor diameter characterized by small distances between the temperature lines (see Fig. 4) indicating a nearly constant mixing temperature. Therefore, we conclude that ice formation is most efficient in Sect. h3.

10 Ice growth rates calculated in a different reactor depth are shown in Table 1. Ice growth rates increased with an increasing reactor depth from 0.75 to $2.82 \mathrm{mg}^{\bullet} \mathrm{s}^{-1}$. The variation of ice growth rates with an increasing depth reflected the variable conditions for ice formation in the different reactor zones $\mathrm{h} 1-\mathrm{h} 3$ reported above. In order of magnitude and normalized to $1 \mathrm{~m}^{2}$, the maximum ice growth rate of $2.82 \mathrm{mg}^{\bullet} \mathrm{s}^{-1}$ is in good 15 agreement with the calculated ice growth rates reported in Fries et al. (2007). Slight variations can be attributed to differences in experimental setup and flow regimes as well as to different growth environments (crystal growths on cooling fins versus grown suspended in air).

The saturation ratio increased with an increasing reactor depth (see Table 1). In a reactor depth of $0.38 \mathrm{~m}$ the saturation ratio reached 1.0 reflecting a saturated air flow. In a greater reactor depth a saturation ratio greater than 1.0 indicates supersaturation with respect to ice. Starting with water vapour introduced by convective diffusion with the centre air at the inlet zone, each consecutive height element enhances the water vapour concentration by molecular diffusion from the wetted filter paper at the reactor 25 wall and the water vapour is transported convectively with the carrier stream. These results verify the conclusions of advanced conditions for ice formation in a greater reactor depth.

In addition to temperatures below $0^{\circ} \mathrm{C}$ conditions particles acting as ice nuclei are needed to form airborne ice crystals. A prerequisite to simulate ice formation under

\section{Airborne ice crystals in a "virtual wall" reactor \\ E. Fries et al.}

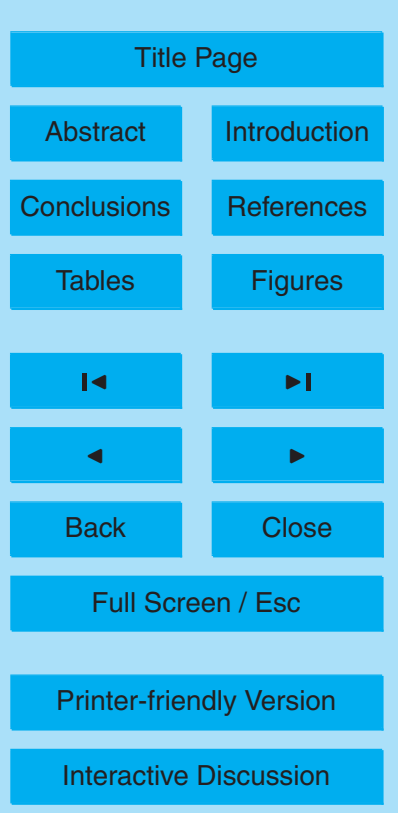


controlled conditions is a precise number concentration of aerosol particles. Therefore, particles in ambient air serving as a carrier gas have to be removed efficiently. At 10 min after starting the cleaning device only two particles per litre in the smallest detectable particle size class of $0.5 \mu \mathrm{m}$ optical diameter were measured. Larger particles $5 \quad(0.7$ to $2.0 \mu \mathrm{m})$ were also present at the beginning, but were totally removed from the carrier gas after $10 \mathrm{~min}$. After six minutes an increase of the particle concentration was observed. A reason for this could be re-suspension and re-entrainment of deposited particles from tubing and other surfaces due to vibrations. This effect was minimized by cleaning the aerosol generator on a regular basis and using short tube lengths. The 10 removal efficiency $E$ was calculated according to Eq. (9)

$\mathrm{E}=\frac{\mathrm{n}_{b}-\mathrm{n}_{a}}{\mathrm{n}_{b}} \cdot 100 \%$

where $\mathrm{n}_{b}$ and $\mathrm{n}_{a}$ represent the number concentration of aerosol particles before and after the cleaning device. After $10 \mathrm{~min}$, the removal efficiency for particles was $99.8 \%$ constituting the time recommended to wait before starting any aerosol generation or 15 growth experiments.

In addition a stable aerosol particle generation is on needed. In Fig. 6, the aerosol number concentration versus time after the flow of scavenging air was switched is shown. A stable number concentration of aerosol particles in the reactor was observed about $15 \mathrm{~min}$ after starting the aerosol generator. This time can be attributed to lag 20 times and deposition of aerosol particles in the tubing. Our results show that the minimum preliminary lead time should be $25 \mathrm{~min}$ to assure a reliable particle supply.

\section{Conclusions}

A new experimental setup was developed to form airborne ice crystals in the laboratory under controlled conditions. The principle was based on the evaporation of water 25 from a physical wall and molecular water vapour diffusion to a laminar sharp down

\section{Airborne ice crystals} in a "virtual wall" reactor

E. Fries et al.

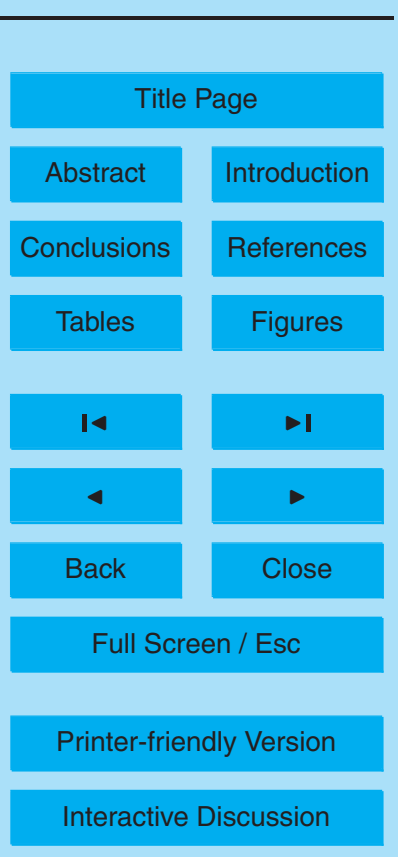


draft "jet stream" of cold air in the centre of a wall independent reactor (WIR). With this experimental design, temperatures below $0^{\circ} \mathrm{C}$ in the whole reactor depth, supersaturation with respect to ice inside the reactor at relevant temperatures, a residence time for airborne ice crystals up to $40 \mathrm{~s}$, minimization of wall effects, and laminar flow 5 conditions were achieved. A maximum ice growth rate was calculated at an amount of water vapour involved in ice crystal growth of $2.82 \mathrm{mg}^{\bullet} \mathrm{s}^{-1}$. Further laboratory studies with the WIR are recommended to study the ability of aerosol particles acting as ice nuclei and to distinguish between gas and particle scavenging with regard to a dynamic uptake of organic compounds by airborne ice crystals.

10 Acknowledgements. Financial support from the Deutsche Forschungsgemeinschaft (DFG) under SFB 641 "The Tropospheric Ice Phase - TROPICE" (project B8) and from the University of Frankfurt is kindly acknowledged.

\section{References}

Benz, S., Möhler, O., Schnaiter, M., Wagner, R., Saathoff, H., and Leisner, T.: Ice nucleation by aqueous and crystalline sulphate particles: New experiments in the aerosol chamber AIDA, Geophys. Res. Abstr., 9, 07697, 2007.

Bundke, U., Nillius, B., Jaenicke, R., Wetter, T., Klein, H., and Bingemer, H.: The fast ice nucleus chamber FINCH, Atmos. Res., doi:10.1016/j.atmosres.2008.02.008., 2008.

Bunz, H., Möhler, O., Naumann, K.-H., Saathoff, H., Schöck, W., and Schurath, U.: The novel aerosol chamber facility AIDA: status and first results, in: Proc. 7th Symp. Physico-chemical behaviour of Atmospheric Pollutants , edited by: Larsen, B., Versino, B., and Angeletti, G., EUR 17482, 673-677, 1996.

De Mott, P. J., Sassen, K., Poellot, M. R., Baumgardner, D., Rogers, D. C., Brooks, S. D., Prenni, A. J., and Kreidenweis, S. M.: African dust aerosols as atmospheric ice nuclei, Geophys. Res. Lett., 30, 14, 173, 2003.

Fries, E., Haunold, W., Jaeschke, W., Hoog, I., Mitra, S. K., and Borrmann, S.: Uptake of gaseous aromatic hydrocarbons by non-growing ice crystals, Atmos. Environ., 40, 54765485, 2006.
ACPD

$8,13017-13042,2008$

Airborne ice crystals in a "virtual wall" reactor

E. Fries et al.

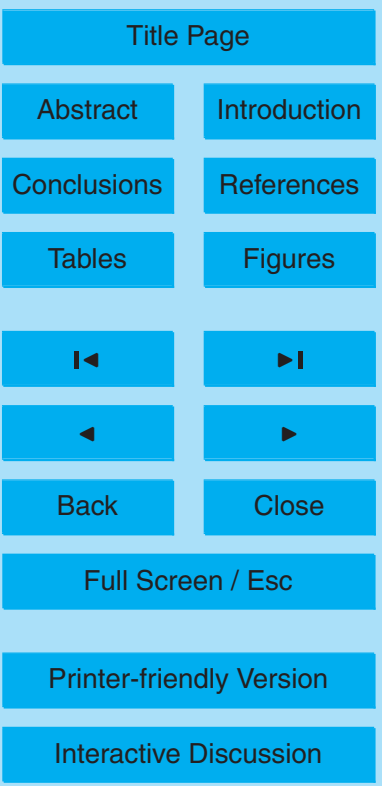


Fries, E., Haunold, W., Starokozhev, E., Jaeschke, W., Mitra, S. K., and Borrmann, S.: Laboratory studies on the uptake of aromatic hydrocarbons by ice crystals during vapour depositional growth, Atmos. Environ., 41, 6156-6166, 2007.

Fries, E.: Interactions of gaseous hydrocarbons with snow and ice, in: Recent Development of Chemistry in Ice, edited by: Takenaka, N., Transworld Research Network 37/661 (1), Kerala, India, 137-162, (ISBN: 978-81-7895-331-1), 2008.

Goss, K.-U.: Adsorption of organic vapors on ice and quartz sand at temperatures below $0^{\circ} \mathrm{C}$, Environ. Sci. Technol., 27, 2826-2830, 1993.

Hartkopf, A. and Karger, B. L.: Study of the interfacial properties of water by gas chromatography, Acc. Chem. Res., 6, 209-216, 1973.

Hoff, J. T., Wania, F., Mackay, D., and Gillham, R.: Sorption of non-polar organic vapors by ice and snow, Environ. Sci. Technol., 29, 1982-1989, 1995.

Huffman, W. A. and Snider, J. R.: Ice-hydrocarbon interactions in the troposphere, J. Geophys. Res., 109, D01302, doi:10.1029/2003JD003778, 2004.

Möhler, O., Bunz, H., Saathoff, H., Schäfer, S., Seifert, M., Tiede, R., Schurath, U., Knopf, D., Schreiner, J., Voigt, Ch., Zink, P., and Mauersberger, K.: The potential of the AIDA aerosol chamber for investigating PSC formation and freezing mechanisms, in: Proc. of the European Workshop on Mesoscale Processes in the Stratosphere, edited by: Carslaw, K. S. and Amanatidis, G. T., EUR 18912, 171-174, 1999.

Orem, M. W. and Adamson, A. W.: Physical adsorption of vapor on ice. II. N-alkanes, J. Colloid Interface Sci., 31, 278-286, 1969.

Rogers, D. C.: Development of a continuous flow thermal gradient diffusion chamber for ice nucleation studies, Atmos. Res., 22, 149-181, 1988.

Rogers, D. C.: Detecting ice nuclei with a continuous-flow diffusion chamber - some exploratory tests of instrument response, J. Atmos. Ocean. Tech., 11, 1042-1047, 1994.

Rogers, D. C., De Mott, P. J., Kreidenweis, S. M., and Chen, Y.: A Continuous Flow Diffusion Chamber For Airborne Measurements of Ice Nuclei, J. Atmos. Ocean. Tech., 18, 725-741, 2001.

Roth, C. M., Goss, K.-U., and Schwarzenbach, R.: Sorption of diverse organic vapors to snow, Environ. Sci. Technol., 38, 4078-4084, 2004.

Salam, A., Lohmann, U., Crenna, B., Lesins, G., Klages, P., Rogers, D., Irani, R., MacGil livray, A., and Coffin, M.: Ice nucleation studies of mineral dust particles with a new continuous flow diffusion chamber, Aerosol Sci. Technol., 40, 134-143, 2006.

Airborne ice crystals in a "virtual wall" reactor

E. Fries et al.

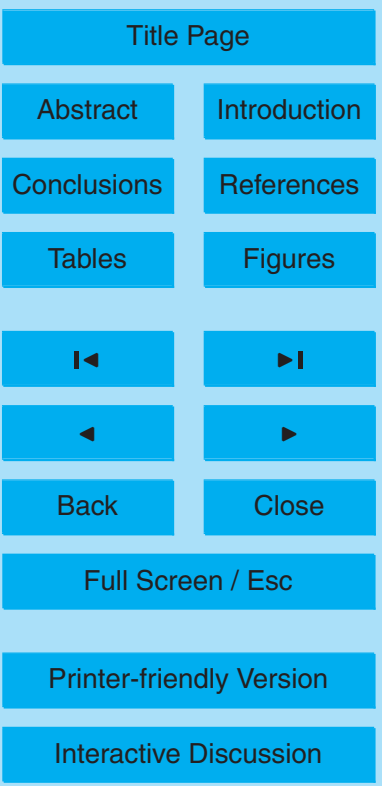


Stratmann, F., Kiselev, A., Wurzler, S., Wendisch, M., Heintzenberg, J., Charlson, R. J., Diehl, K., Wex, H., and Schmidt, S.: Laboratory studies and numerical simulations of cloud droplet formation under realistic supersaturation conditions, J. Atmos. Oceanic Technol., 21, 876887, 2004.

5 Wex, H., Kiselev, A., Ziese, M., and Stratmann, F.: Calibration of LACIS as a CCN detector and its use in measuring activation and hygroscopic growth of atmospheric aerosol particles, Atmos. Chem. Phys., 6, 4519-4527, 2006, http://www.atmos-chem-phys.net/6/4519/2006/.

\section{ACPD}

$8,13017-13042,2008$

\section{Airborne ice crystals} in a "virtual wall" reactor

E. Fries et al.

Title Page

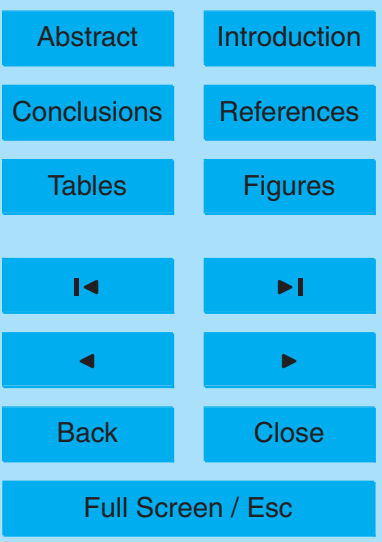

Printer-friendly Version

Interactive Discussion 


\section{ACPD}

$8,13017-13042,2008$

Table 1. Results of hydrodynamic considerations and ice mass calculations. ( $\Delta \mathrm{C}$ is the differ ence of water vapor concentration between cold air at the reactor centre and warm moist air at the walls, $Q_{M, i}$ is the ice mass grown by molecular diffusion per time, $Q_{C}$ is the convectively transported amount of water vapour at the inlet zone, $C$ is the water vapour concentration at the inlet temperature, $\mathrm{C}_{\text {sat }}$ is the saturation vapour concentration, and $\mathrm{S}$ is the saturation ratio).

\begin{tabular}{llllllll}
\hline $\begin{array}{l}\text { abs. depth } \\
{[\mathrm{cm}]}\end{array}$ & $\begin{array}{l}\text { rel. depth } \\
{[\mathrm{h}-18 \mathrm{~cm}]}\end{array}$ & $\begin{array}{l}\Delta \mathrm{C} \\
{\left[\mathrm{g} \cdot \mathrm{m}^{-3}\right]}\end{array}$ & $\begin{array}{l}\mathrm{Q}_{M, i} \\
{\left[\mathrm{mg} \cdot \mathrm{s}^{-1}\right]}\end{array}$ & $\begin{array}{l}\mathrm{Q}_{M, i}+\mathrm{Q}_{C} \\
{\left[\mathrm{mg} \cdot \mathrm{s}^{-1}\right]}\end{array}$ & $\begin{array}{l}\mathrm{C} \\
{\left[\mathrm{g} \cdot \mathrm{m}^{-3}\right]}\end{array}$ & $\begin{array}{l}\mathrm{C}_{\mathrm{sat}} \\
{\left[\mathrm{g} \cdot \mathrm{m}^{-3}\right]}\end{array}$ & $\mathrm{S}$ \\
\hline 18 & 0 & 5.25 & 0 & 0.75 & 1.52 & 2.75 & 0.6 \\
28 & 10 & 4.82 & 0.40 & 1.15 & 2.33 & 2.93 & 0.8 \\
38 & 20 & 4.39 & 0.37 & 1.52 & 3.08 & 3.08 & 1.0 \\
48 & 30 & 3.96 & 0.33 & 1.85 & 3.74 & 3.20 & 1.2 \\
58 & 40 & 3.53 & 0.29 & 2.15 & 4.34 & 3.28 & 1.3 \\
68 & 50 & 3.10 & 0.26 & 2.41 & 4.86 & 3.34 & 1.5 \\
78 & 60 & 2.67 & 0.22 & 2.63 & 5.31 & 3.38 & 1.6 \\
88 & 70 & 2.24 & 0.19 & 2.82 & 5.69 & 3.38 & 1.7 \\
\hline
\end{tabular}

Airborne ice crystals in a "virtual wall" reactor

E. Fries et al.

Title Page

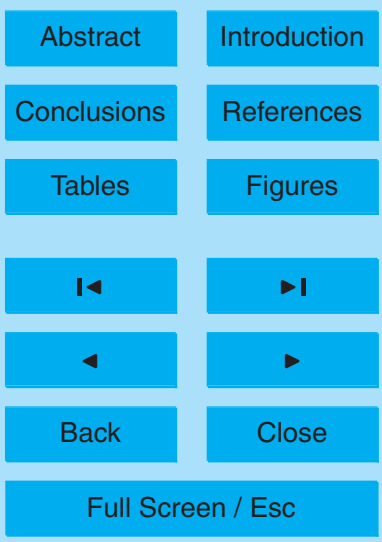

Printer-friendly Version

Interactive Discussion 


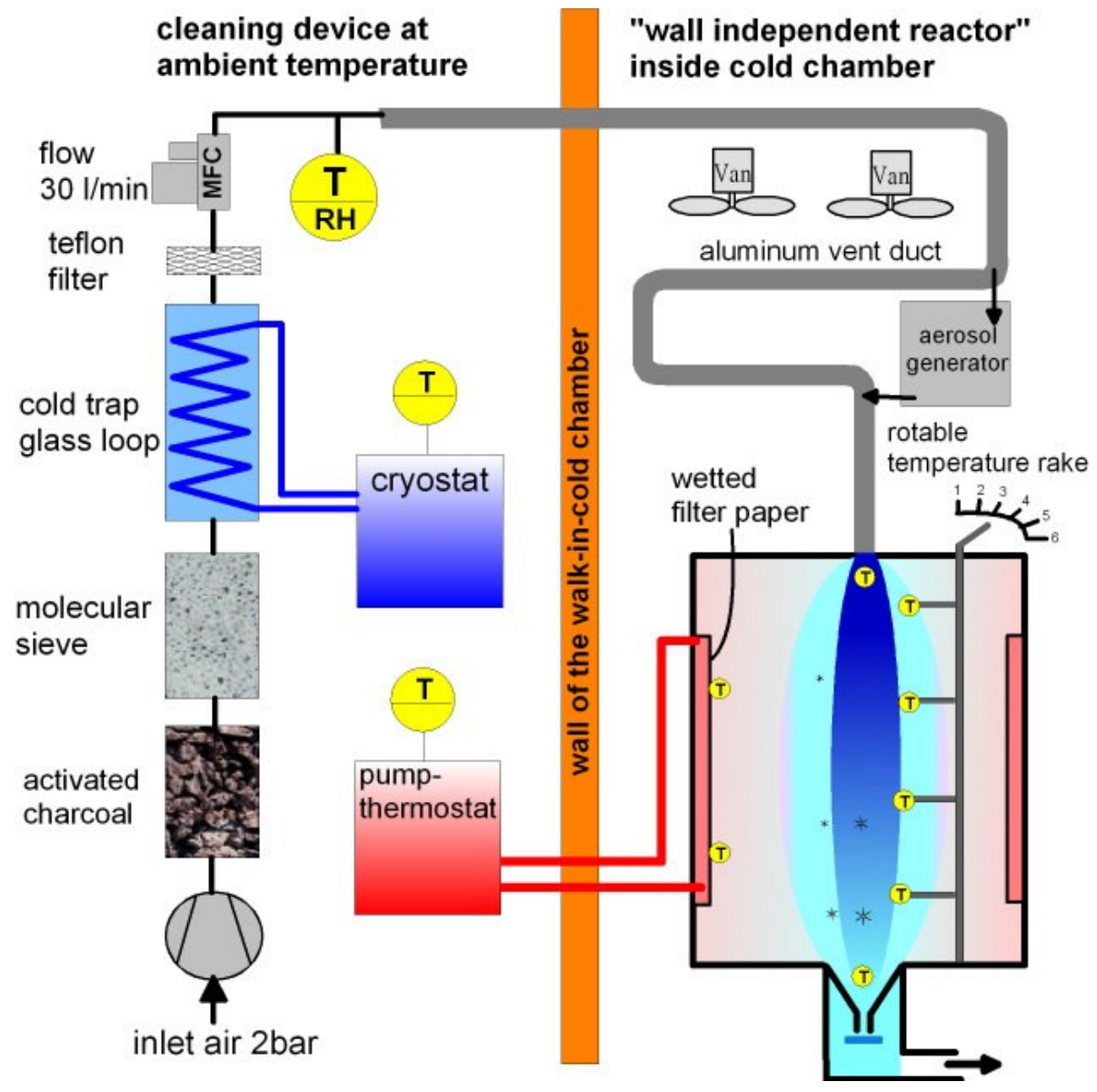

\section{ACPD}

8, 13017-13042, 2008

Airborne ice crystals in a "virtual wall" reactor

E. Fries et al.

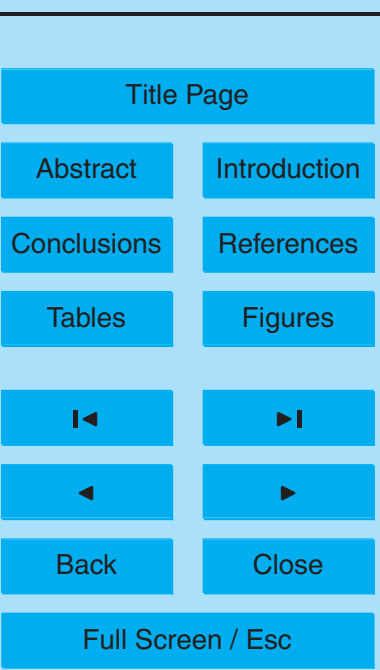

Printer-friendly Version

Fig. 1a. Experimental setup and gas flow scheme.

Interactive Discussion 


\section{Aerosol generator}

\section{ACPD}

\section{8, 13017-13042, 2008}

airborne particles

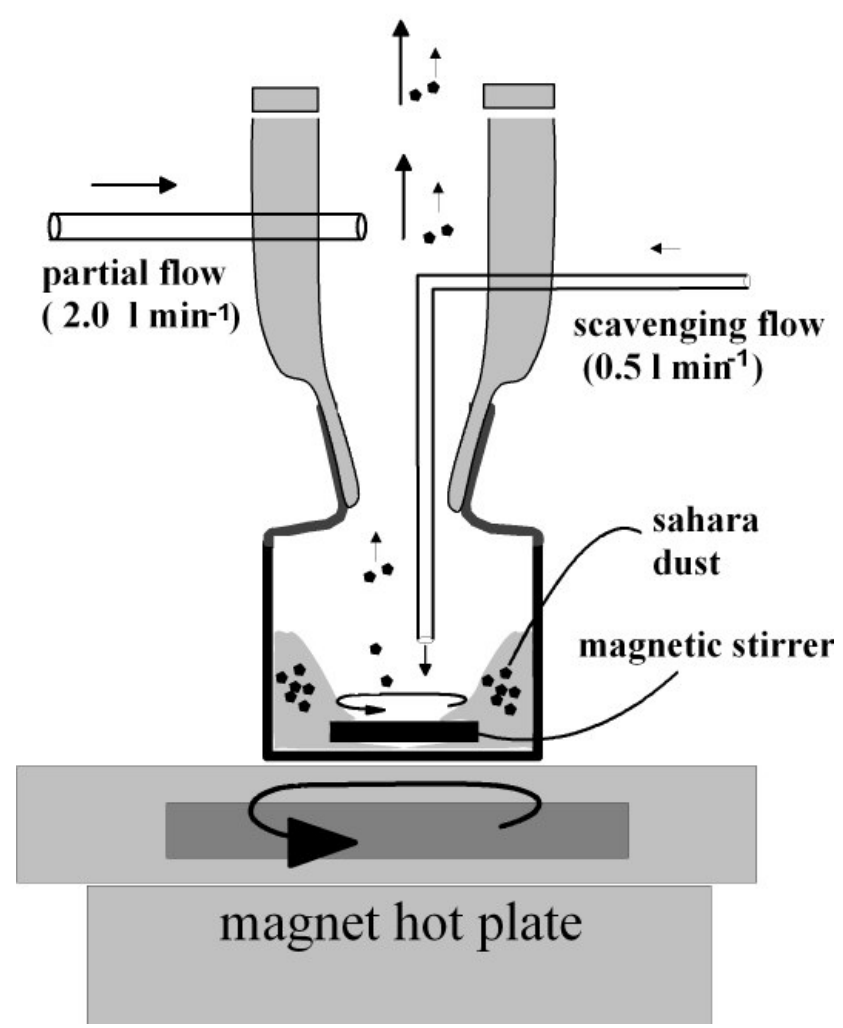

Airborne ice crystals in a "virtual wall" reactor

E. Fries et al.

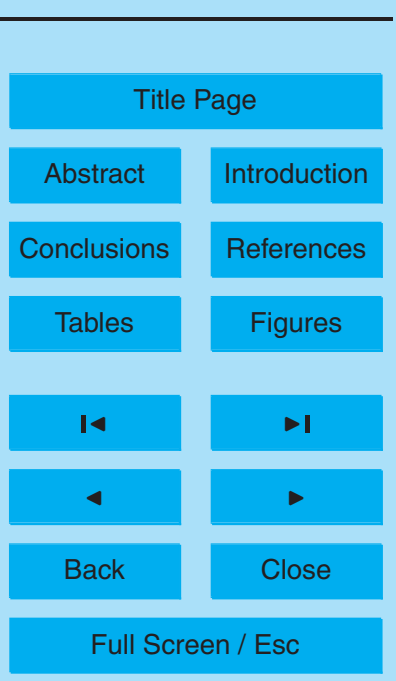

Printer-friendly Version

Interactive Discussion

Fig. 1b. Principle of the aerosol generator. 


\section{ACPD}

8, 13017-13042, 2008

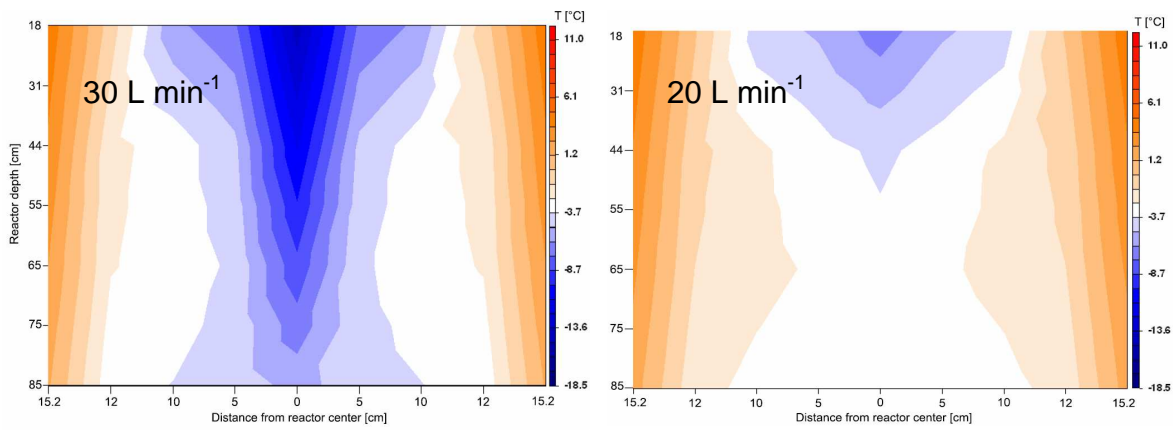

Airborne ice crystals in a "virtual wall" reactor

E. Fries et al.

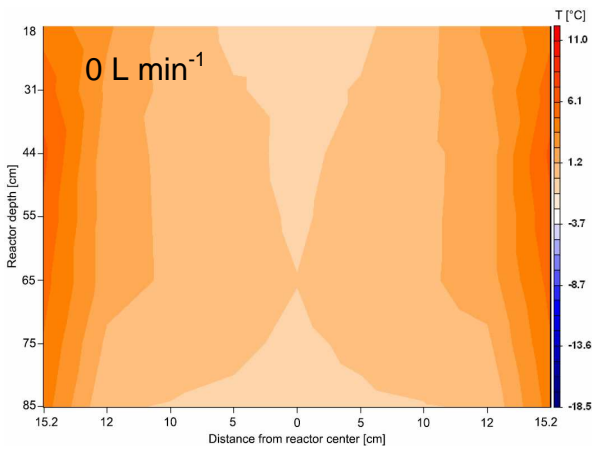

Introduction

Abstract References

Conclusions

Figures

Tables

14

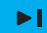

4

Back

Close

Full Screen / Esc

Fig. 2a. Temperature profiles at different flow rates of $30 \mathrm{~L} \cdot \mathrm{min}^{-1}, 20 \mathrm{~L} \cdot \mathrm{min}^{-1}$, and $0 \mathrm{~L} \cdot \mathrm{min}^{-1}$ at a constant temperature of the physical wall of $+5^{\circ} \mathrm{C}$ and a constant inlet temperature of $-20^{\circ} \mathrm{C}$. 


\section{ACPD}

8, 13017-13042, 2008
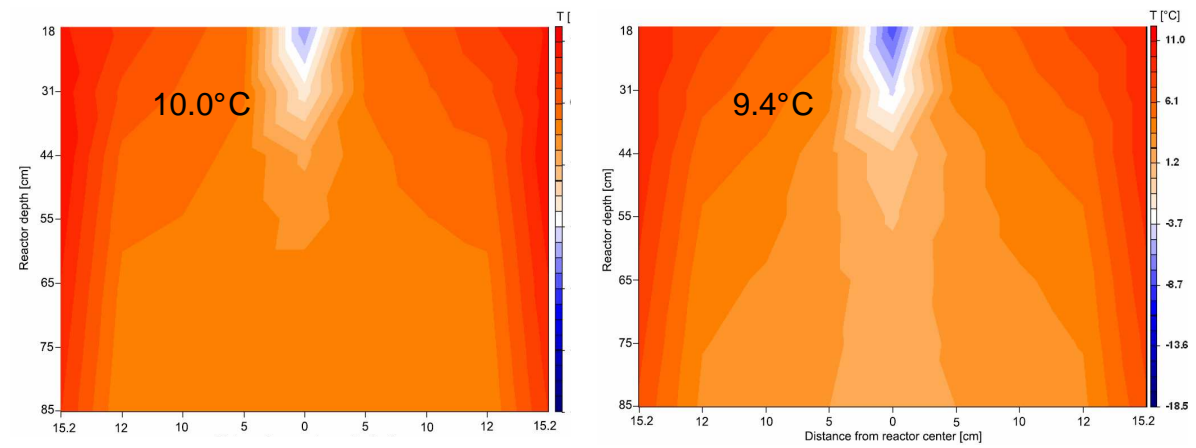

Airborne ice crystals in a "virtual wall" reactor

E. Fries et al.

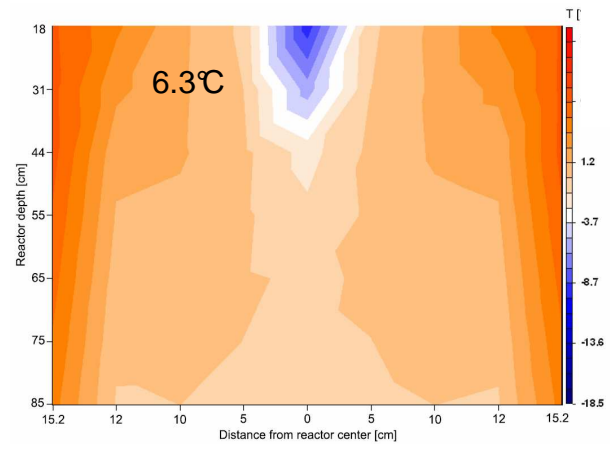

Title Page

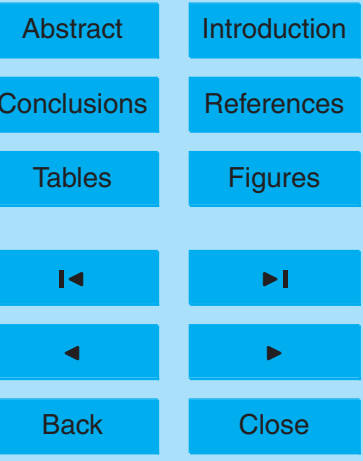

Full Screen / Esc

Fig. 2b. Temperature profiles at different physical wall temperatures of $+10.0^{\circ} \mathrm{C},+9.4^{\circ} \mathrm{C}$ and $6.3^{\circ} \mathrm{C}$ at constant flow rate of $30 \mathrm{~L} \cdot \mathrm{min}^{-1}$ and a constant inlet temperature of $-20^{\circ} \mathrm{C}$.

Printer-friendly Version

Interactive Discussion 


\section{ACPD}

8, 13017-13042, 2008

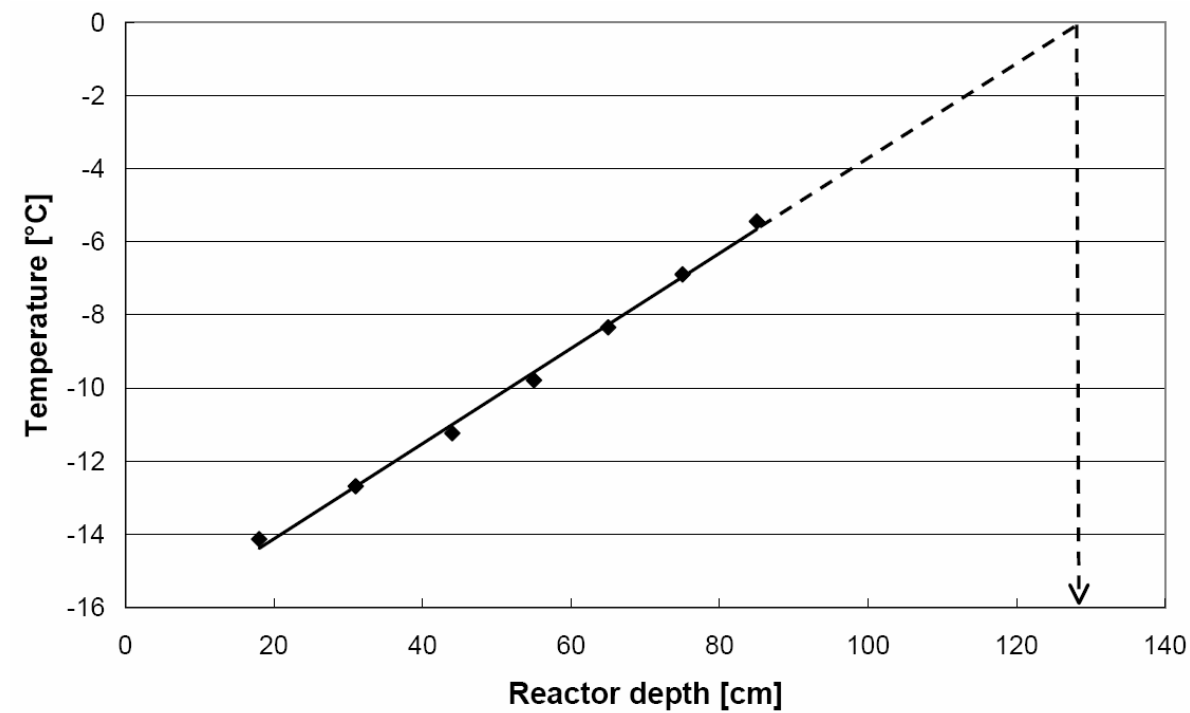

Fig. 3. Temperature at the centre of the WIR inside the "jet stream" in a different reactor depth at a physical wall temperature of $+5^{\circ} \mathrm{C}$ and a constant inlet temperature of $-20^{\circ} \mathrm{C}$ (the extrapolation and the arrow show the maximum hypothetical length of the reactor up to which ice crystal growth would be possible).
Airborne ice crystals in a "virtual wall" reactor

E. Fries et al.

Title Page

\section{Full Screen / Esc}

Printer-friendly Version

Interactive Discussion 


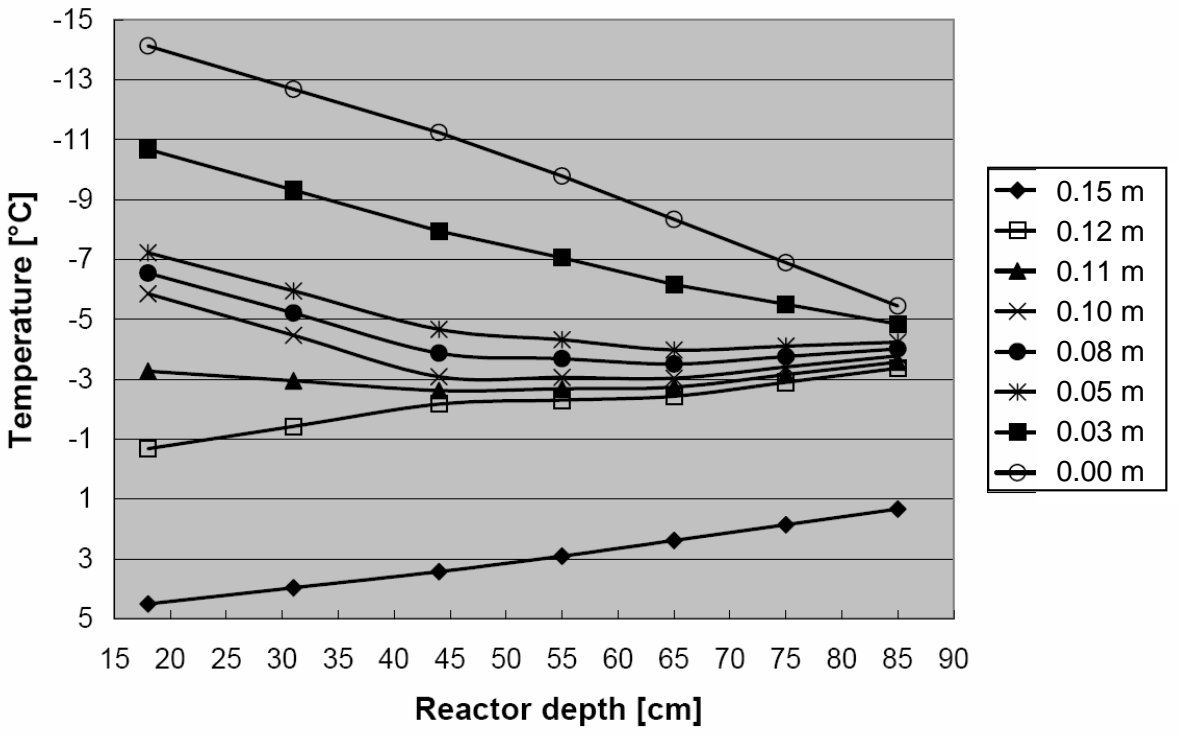

Fig. 4. Temperatures in a different reactor depth at different distances between 0 and $0.15 \mathrm{~m}$ from the reactor centre.

\section{ACPD}

$8,13017-13042,2008$

Airborne ice crystals in a "virtual wall" reactor

E. Fries et al.

Title Page

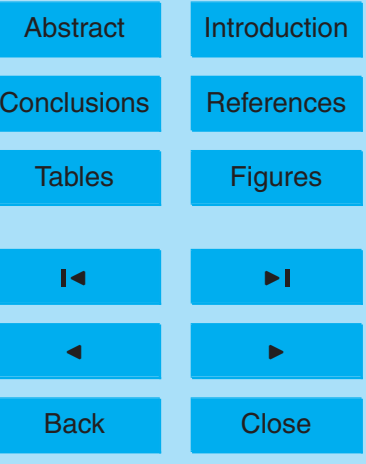

Full Screen / Esc

Printer-friendly Version

Interactive Discussion 


\section{ACPD}

\section{8, 13017-13042, 2008}

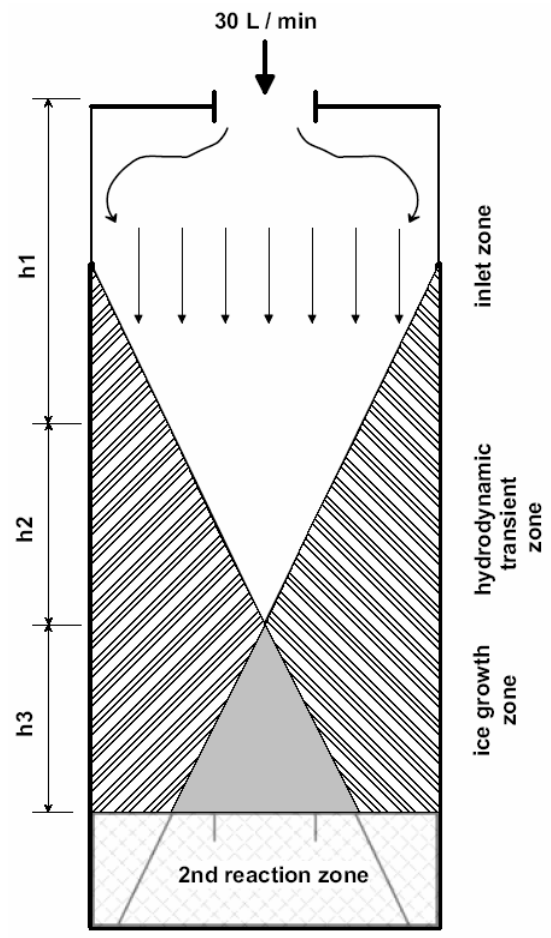

\section{Airborne ice crystals}

in a "virtual wall" reactor

E. Fries et al.

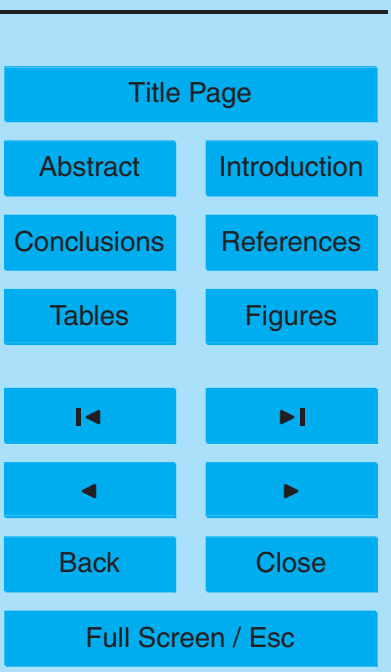

Fig. 5. Partitioning of the WIR into different sections based on hydrodynamic conditions inside.

Printer-friendly Version

Interactive Discussion 


\section{ACPD}

8, 13017-13042, 2008

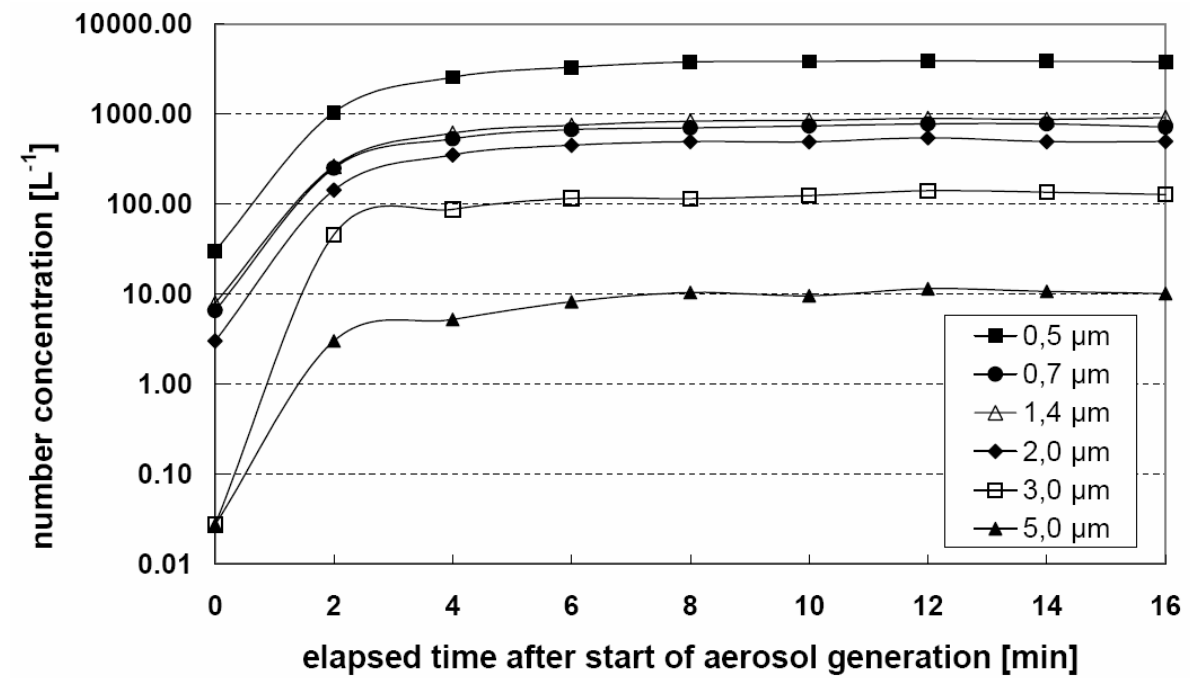

Fig. 6. Stabilization of the particle number concentration after starting the aerosol generation for different particle sizes $(0.5-5.0 \mu \mathrm{m})$.
Airborne ice crystals in a "virtual wall" reactor

E. Fries et al.

Title Page

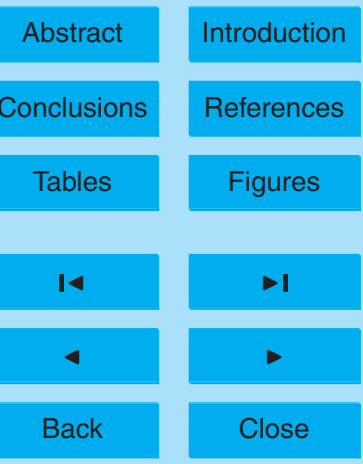

Full Screen / Esc

Printer-friendly Version

Interactive Discussion 